\title{
EDIFICAÇÃO E LOTEAMENTO SUSTENTÁVEIS NO RIO VERMELHO
}

\section{Autora: Gladys Ilka Klein Taparello (UFSC) Orientação: Lisiane Ilha Librelotto, Dra. (UFSC)}

\section{INTRODUÇÃO}

Muito se fala sobre sustentabilidade atualmente mas, apesar de todo o discurso, ainda são poucas as ações que a promovam no dia a dia. Por outro lado, percebe-se que lentamente a indústria da construção civil vem buscando tornar seu processo produtivo menos danoso ao meio ambiente e à sociedade. A maioria das iniciativas de produção sustentável, no entanto, requerem tecnologia de ponta ou estão em um estágio muito inicial de desenvolvimento, sendo praticamente artesanais.

A sustentabilidade é baseada em três aspectos: o ambiental, o econômico e o social, que devem coexistir em equilíbrio. Esse deve ser o objetivo final a ser alcançado através um processo contínuo baseado em intenções renovadas continua e progressivamente.

Assim sendo, sustentabilidade diz respeito a ações e intenções que procuram gerar meIhor qualidade de vida para as pessoas através do fortalecimento das comunidades nos aspectos econômicos e sociais, preservando os recursos naturais para as gerações futuras.

A proposta deste trabalho foi estudar a sustentabilidade na construção civil e os requisitos para uma edificação com o menor dano possível ao meio ambiente, ao mesmo tempo em que promova a qualidade de vida das pessoas, sendo economicamente viável.

Foi elaborado o projeto arquitetônico de uma residência unifamiliar, com detalhamento dos sistemas. Para isso, foram definifidos três objetivos específicos:

- Definir o perfil de família apontado pelo estudo da área;

- Definir os sistemas estrutural, construtivo e bioclimáticos de modo que atendam aos critérios de sustentabilidade estudados;

- Propor a criação de um loteamento baseado na sustentabilidade e de uma residência modelo em um dos lotes.

O loteamento sustentável é proposto como uma base na qual se insere a residência sustentável. A intenção é estudar os itens necessários para definir diretrizes para a implementação do loteamento, abordando as seguintes questões de:

- implantação;

- zoneamentos;

- sistemas de tratamento de esgoto;

- sistemas de abastecimento de água;

- sistemas de reuso de águas cinzas;

- sistemas de captação de água da chuva;

- escolha de materiais para áreas comuns;

- projeto paisagístico de áreas comuns;

- manual do proprietário.

A escolha do bairro Rio Vermelho se deu por quatro motivos: o crescimento urbano desordenado, principalmente na última década; a falta de infraestrutura; o baixo IDHL (2002); e também o vínculo afetivo.

O distrito de São João do Rio Vermelho é um dos 12 Distritos administrativos do município de Florianópolis e está localizado na costa nordeste da llha de Santa Catarina. Possui 10.756 habitantes em uma área de $31.36 \mathrm{~km}^{2}$. $65 \%$ dos mo- 
radores está abaixo dos 40 anos, caracterizando uma população bastante jovem. Quase $60 \%$ da população possui algum tipo de rendimento, que tem o valor médio mensal de $R \$ 12.68,83$, o que correspondia a quase três salários mínimos da época do censo IBGE. Aproximadamente 95\% da população é alfabetizada. (IBGE, 2010).

\section{CRITÉRIOS DE SUSTENTABILIDADE - 0 SELO CASA AZUL}

O Selo Casa Azul é uma certificação de sustentabilidade para edificações residenciais criada em conjunto pela Caixa Econômica Federal e diversas universidades. Possui três níveis de certificação, que correspondem ao cumprimento de determinado número de critérios obrigatórios e opcionais. Estes critérios estão agrupados em seis categorias, a saber:

- qualidade urbana;

- projeto e conforto;

- eficiência energética;

- conservação de recursos materiais;

- gestão da água;

- práticas Sociais.

A decisão de utilizar o Selo Casa Azul como guia para a definição de critérios de sustentabilidade se deu pelo fato de esta certificação abranger os aspectos econômico, social e ambiental da sustentabilidade, enquanto a maioria das certificações prioriza o aspecto ambiental.

\section{ESCOLHA DA ÁREA DE ESTUDO}

A partir do mapa de cheios e vazios do bairro, foram identificadas as regiões com maior densidade de edificações e a disponibilidade de infraestrutura. Em seguida foi fanalisado o atendimento aos critérios de qualidade do entorno,[ em algumas regiões: a existência de transporte público, comércio e serviços num raio de $1 \mathrm{~km}$, de escola pública num raio de $1,5 \mathrm{~km}$, e de equipamentos de lazer e posto de saúde em $2,5 \mathrm{~km}$. Por fim foram localizados lotes que possuíssem dimensões adequadas para a implantação de loteamento.
Com base nesses estudos foi escolhido o lote localizado na Rua Cândido Pereira do Anjos, próximo à Rua Luiz Duarte Soares. Com uma área de $196.231,72 \mathrm{~m}^{2}$, o lote é praticamente plano, com exceção de uma pequena elevação na extrremidade nordeste. Há ainda, uma nascente de água na porção sudeste e na lateral leste, o lote faz divisa com o Parque Estadual do Rio Vermelho, uma área de vegetação arbustiva antes das dunas da praia das Aranhas.

Segundo o Plano Diretor de Florianópolis de 2014, o terreno faz parte de uma Área Residencial Predominante, com Taxa de Ocupação de 50\% e número máximo de 2 pavimentos. Na porção frontal do lote há uma Área Residencial Mista, com os mesmos valores de Taxa de Ocupação e número máximo de pavimentos do resto da área do terreno.

\section{A PROPOSTA DO LOTEAMENTO SEGUIU AS SEGUINTES DIRETRIZES}

a) Topografia:

- uso comum da elevação para usufruto da vista;

- ocupação predominantemente na parte mais plana do terreno, observando o escoamento das águas pelas curvas de níveis.

b) águas:

Aproximação das pessoas da nascente do rio Vermelho atravéz da proposição de espaços de estar na APP e de áreas de uso público voltadas para a nascente;

- prevenção de alagamentos: distribuindo os lotes fora dos caminhos das águas; e proposição de áreas de lazer públicas nas áreas de retenção de águas pluviais em caso de fortes chuvas.

c) Vegetação:

- proposta de reflorestamento com árvores nativas da mata atlântica nas APP;

- previsão de horta e pomar: dando-se preferência por espécies nativas e espécies exóticas adaptadas ao clima;

paisagismo: preferência por espécies nati- 
vas e de baixa manutenção;

- estação de tratamento de esgoto com sistema de raízes: espécies nativas adequadas a função; tratamento dos resíduos com tanques de cloração para liberação da água no meio ambiente.

d) Uso e ocupação:

- concordância com o Plano Diretor vigente, que estabelece número o máximo de pavimentos em 2, taxa de ocupação de $50 \%$ e índice de aproveitamento 1; ciais:

- desmembramentos de lotes residen-

$40 \%$ até três ( 42 lotes)

$35 \%$ até dois ( 37 lotes)
$25 \%$ não podem ser desmembrados ( 26 lotes);

- concentração de comércios e serviços nas bordas: acesso facilitado a população do bairro como um todo;

- presença de atividades públicas na parte central: estímulo à circulação de pessoas durante o dia.

e) Circulação

- interrupção das vias laterais para evitar a ocupação ilegal da APP;

- vias com passeios alargados, dando-sepreferência aos pedestres e espaço de lazer para crianças próximo às casas;

- vias preferenciais para pedestres na par

Figura 1: planta baixa

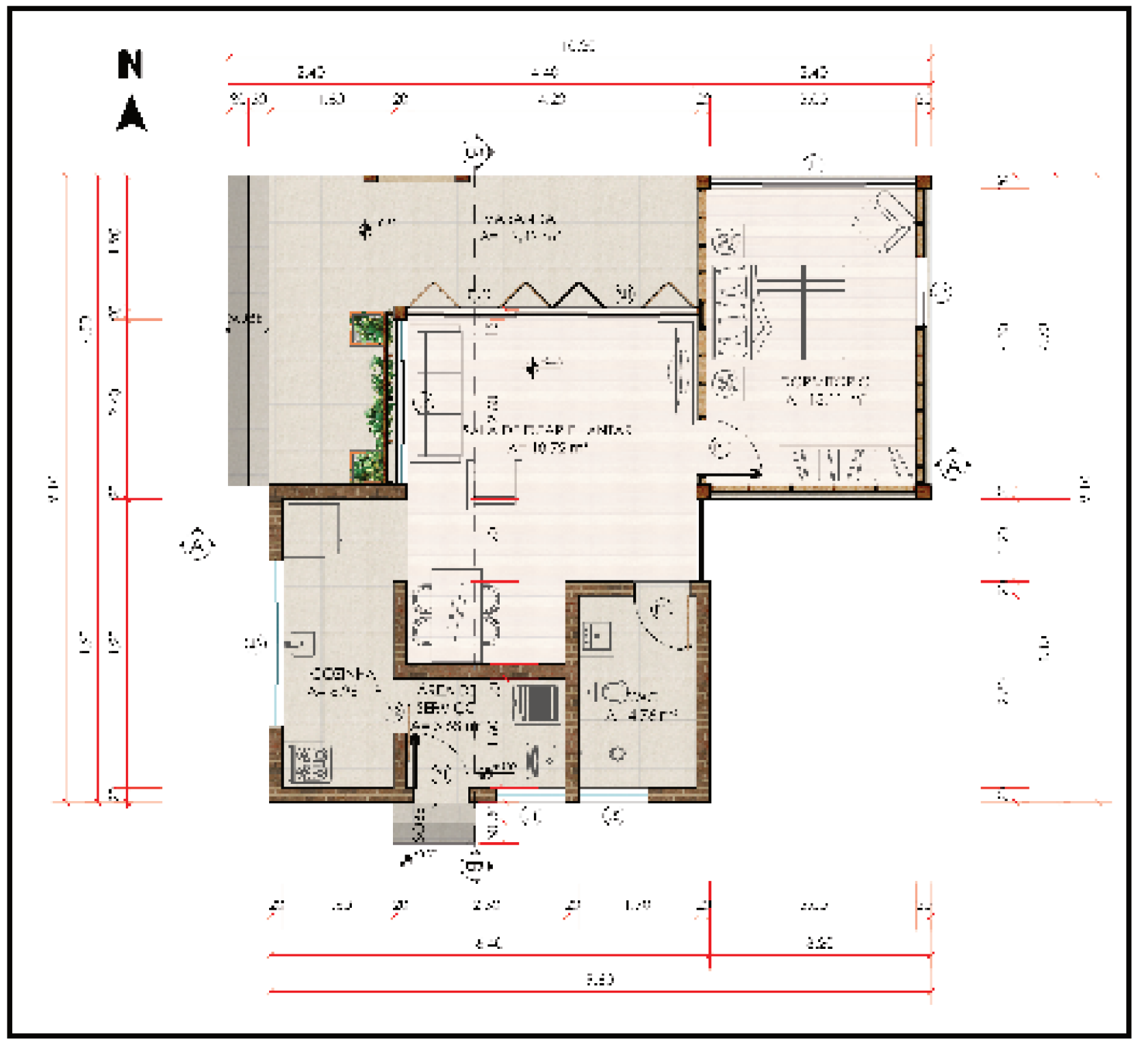

Fonte: Autores 
Figura 2: corte aa ecotelhado

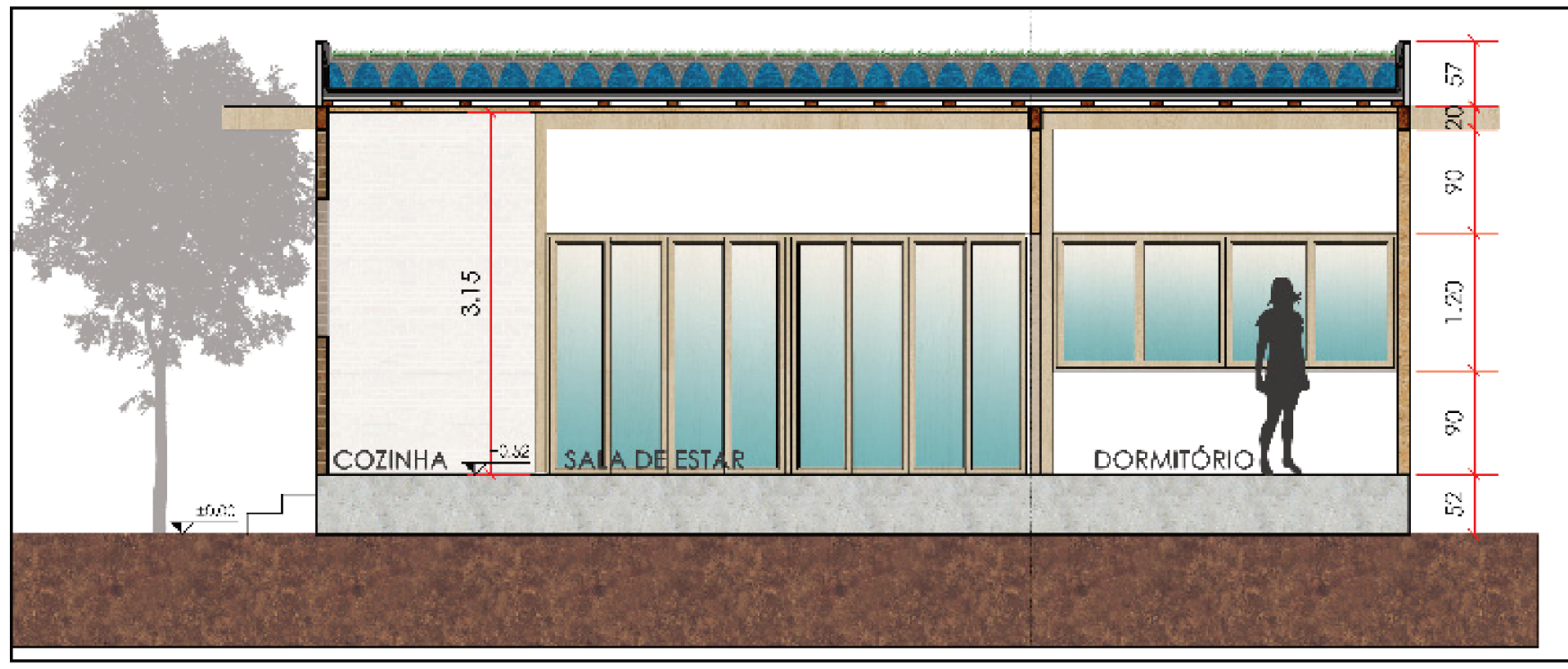

Fonte: Autores

"A sustentabilidade é baseada em três aspectos:

o ambiental, o econômico e o social, que devem coexistir em equilíbrio."

Figura 3: corte bb ecotelhado

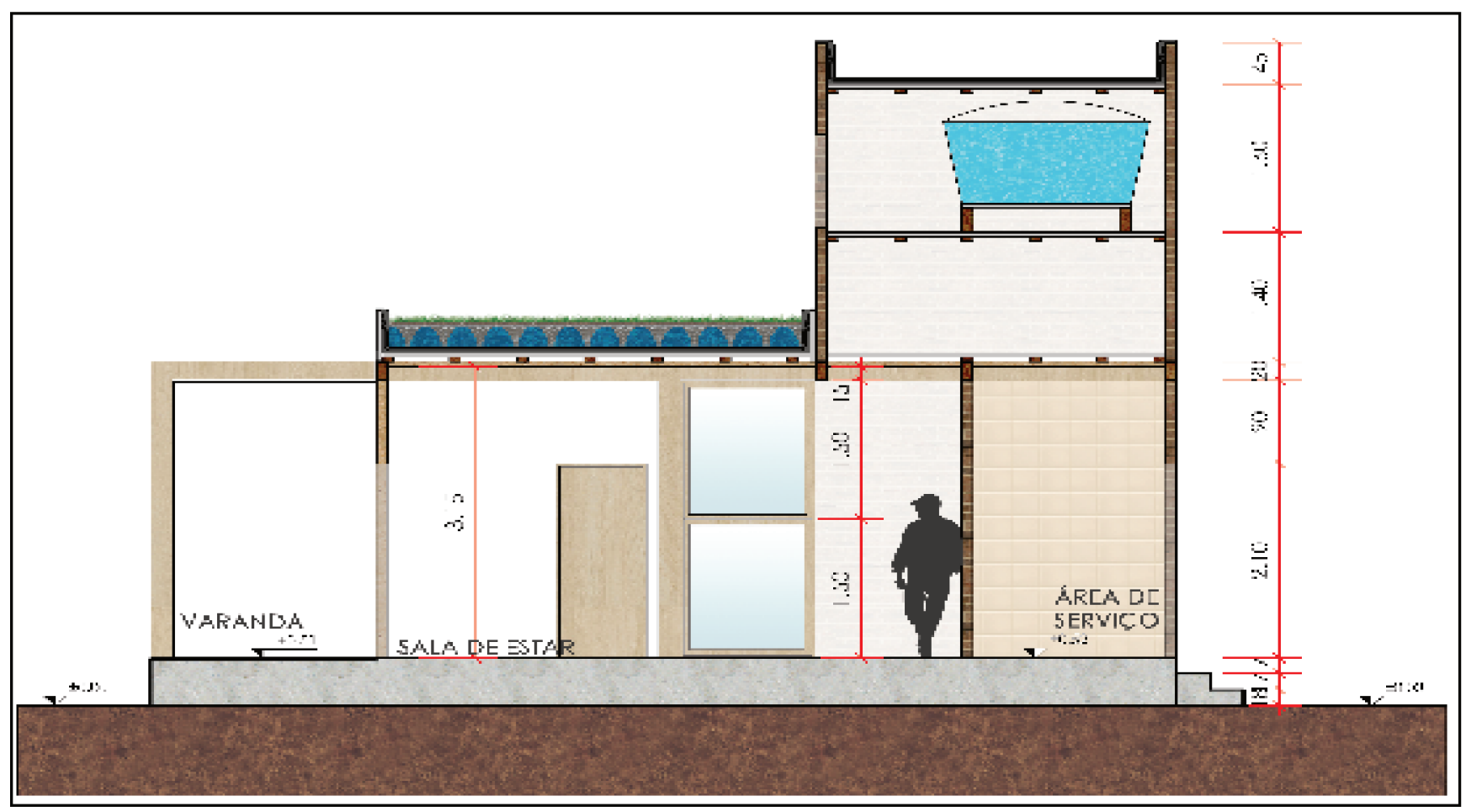

Fonte: Autores 
te leste para diminuir o fluxo de veículos em setor delicado;

Passarela até a praia: caminho por cima das dunas e vegetação até a praia, com a mínima interferência possível na APP;

Desenho orgânico das vias para incentivar os motoristas a andarem em baixa velocidade;

Ciclovia nas ruas Cândido Pereira dos Anjos e Luiz Duarte Soares, além da via central do loteamento;

Travessia de pedestres no nível do passeio.

\section{DIRETRIZES PARA A EDIFICAÇÃO}

O projeto de edificação, por sua vez, seguiu as seguintes diretrizes:

- múltiplas variações formais e funcionais;

- possibilidade de ampliação;

- ambientes modulares, propiciando composições variadas;

- utilização de materiais com baixos valores de Energia Incorporada;

Sistemas de reaproveitamento de águas pluviais, de captação de energia elétrica solar, de aquecimento solar de água;

- utilização de materiais com boa capaci-

Figura 4: planta loteamento

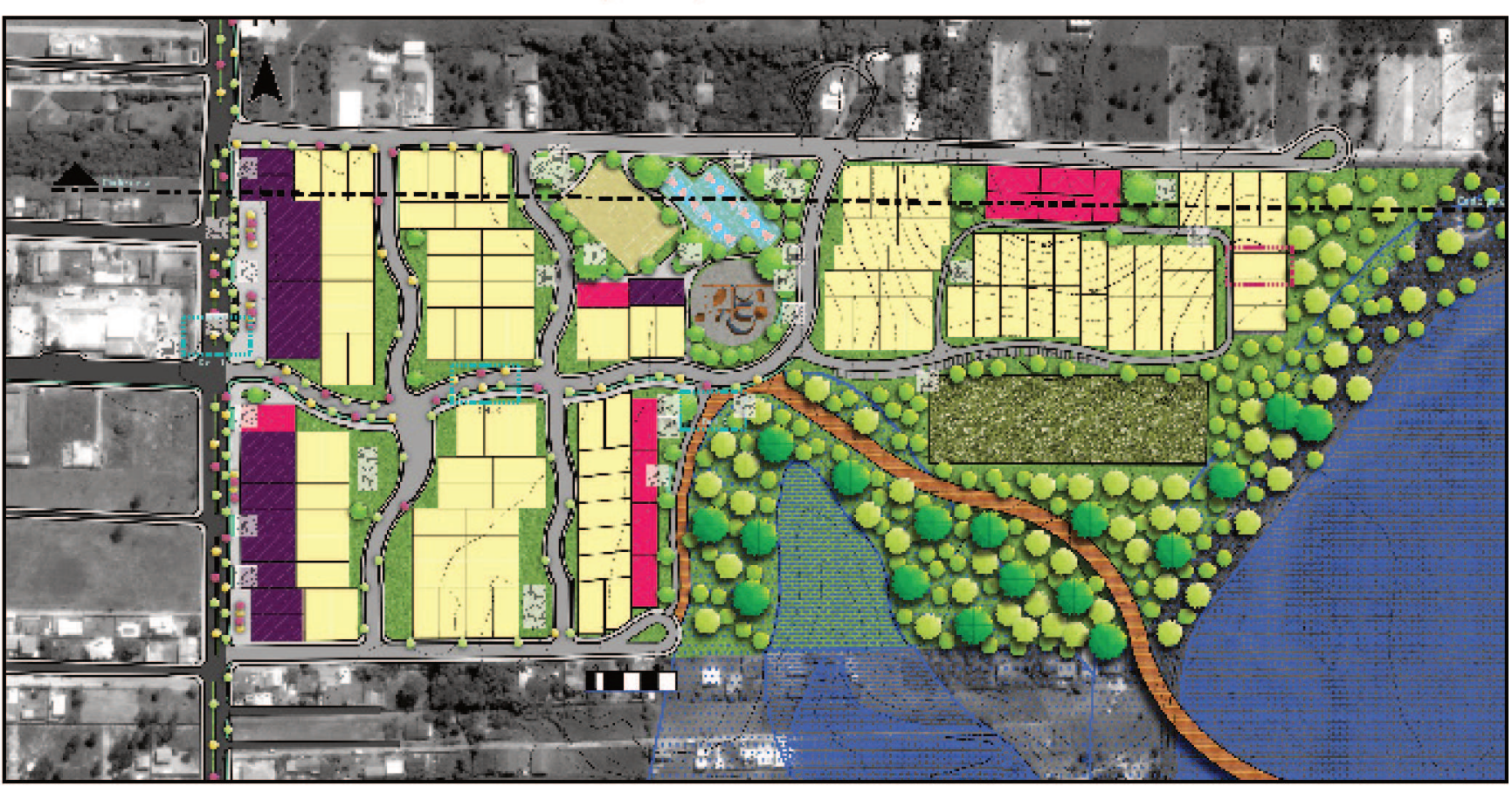

Fonte: Autores 